Only if he wishes to know about developments in the antiviral field is he likely to go away more or less empty handed, but since the authors have largely, though not by any means entirely, confined themselves to "antibiotics" in the strict sense, this particular deficiency may be easily forgiven.

H.R. Perkins is Professor of Microbiology at the University of Liverpool.

\section{Truncation at length}

\author{
Francisco J. Ayala
}

Genetic Variability. By Christopher Wills. Pp.312. ISBN 0-19-857570-X. (Clarendon/Oxford University Press: 1981.) $£ 24$, $\$ 49.50$.

THE existence of inheritable variation is, as Darwin saw it, a necessary condition for evolution. The genetic variants present in a population at a given time define the evolutionary changes that are possible in the population. It has become established during the past two decades that populations of all sorts of organisms store an enormous wealth of genetic variation. In this book, Christopher Wills, a distinguished population geneticist of the University of California at San Diego, deals only in passing with the issue of how much variation is there, but explores in depth the mechanisms that account for the variation.

This is a roman à clef. Wills's argument is that genetic variation is maintained largely by natural selection operating according to the truncation model. We may envisage the distribution of organisms according to their phenotypic fitness. A certain proportion of the organisms will survive and reproduce. According to the truncation model, the fitness value below which no survival occurs is not absolute but depends on the actual fitness distribution. The implications of truncation with respect to many central problems of population genetics are investigated at length, and most are published here for the first time this is undoubtedly the most significant contribution of the book. Among the important conclusions reached, one is that the gene is the unit of selection (Chapters 8 and 9). With truncation, the strength of linkage disequilibrium in outbred populations is not a function of selection but of the population size.

According to Wills, the most compelling evidence in favour of truncation selection

François Jacob's The Logic of Life: A History of Heredity (reviewed as The Logic of Living Systems in Nature 251, 81; 1974) has been reissued by Pantheon Books, New York. The book includes a new preface by the author, and costs $\$ 7.95$ in paperback. is negative. If the fitness effects of each locus interact multiplicatively, then the maintenance of multiple polymorphisms would require a considerable segregational load - "highly homozygous populations should be extremely unfit"' (p.36). Astonishingly, on the following page Wills states that this is "contrary to observation". This ignores a number of experiments (e.g. M.L. Tracey and F.J. Ayala, Genetics 77, 569-589; 1974) showing that, when fitness as a whole is measured under population conditions, the inbreeding depression is enormous sufficiently large to account for hundreds of polymorphisms even if fitness interactions are multiplicative.

Wills asserts that whether or not most genetic variation is selectively neutral is a question "impossible to resolve, since it is impossible to prove the absence of something" (p. vii). This last phrase is obviously wrong, since I can prove to the satisfaction of any reasonable person that there is no 747 Boeing airplane in my office. Most importantly, the statement misconstrues the aims and methods of science. The neutrality theory has been extremely fertile because it makes certain predictions about genetic variation, rates of evolution and so on. If such predictions were correct, the theory would be corroborated. Natural selection might be involved, but if it could be ignored in accounting for the relevant phenomena, there would be no reason to incorporate it in our explanations. One need not take into account the craters of Venus when explaining planetary motions. The point is a substantive one: the only hypotheses and the only parameters that are acceptable in science are those that are necessary in order to account for empirical phenomena.

Francisco J. Ayala is Professor of Genetics at the University of California at Davis.

\title{
A time and place for fire and brimstone
}

\section{Peter J. Smith}

Volcanoes of the World: A Regional Directory, Gazetteer, and Chronology of Volcanism during the Last 10,000 Years. By T. Simkin et al. Pp.248. ISBN 0-12-787478-X. (Hutchinson Ross: 1981.) $\$ 19.75, £ 13.20$.

PEOPLE have been compiling lists of volcanoes since at least 1650 , when Varenius tabulated 27 examples. Two centuries later, Humboldt raised the total to 407; and, when complete, the IAVCEI's Catalog of Active Volcanoes (begun 1951) will contain details of about 900 . The magnificent Smithsonian Institution volume under review here, however, lists no fewer than 1,343 volcanoes known or likely to have been active during the Holocene and 5,564 dated eruptions from about $8300 \mathrm{BC}$ onwards, all arranged regionally and chronologically, respectively, in two large tables, to which are added a gazetteer and a bibliography.

Volcanoes of the World is thus the most complete and easily accessible compilation of volcanoes and volcanic activity now available, although the authors themselves hardly dare breathe the word "complete" in this context because their listings are anything but. For a start, most volcanism takes place on the sea floor and almost all of that goes unnoticed. Even on the continents, however, there are still regions in which much volcanic activity goes unrecorded; and if that can happen in a highly populated world shrunk by modern communications, how much more extensive must have been the omissions of the past. Indeed, Simkin and his colleagues demonstrate graphically that both the total number of known volcanoes and the number of known active volcanoes have increased roughly exponentially over the past 600 years, which suggests either that the Earth is about to be overwhelmed by volcanic activity or that the perceived volcanic state of the planet is highly dependent upon reporting efficiency.

Under such circumstances, attempts to correlate known historic volcanism with other phenomena must be undertaken warily. Even so, the compilations at the heart of this volume will be a boon to a remarkably wide range of scholars quite apart from geologists. Biologists interested in colonization will find here the 96 eruptions known to have formed islands; glaciologists can easily pick out the 15 volcanoes with known subglacial eruptions; agriculturalists may like to know of the 181 volcanoes with eruptions known to have destroyed arable land; climatologists will look for those volcanoes known to have ejected particularly large amounts of ash and dust into the atmosphere; anthropologists might examine the listed eruptions known to have severely affected communities; and so on.

In short, Volcanoes of the World is, a splendid work of considerable interdisciplinary value and will become even more so if, as the authors hope, feedback from readers and other interested parties enables some of the many gaps to be filled. For this is not a one-off job but the first step in a continuing attempt to build as extensive a file as possible on the statistical aspects of the world's volcanism.

Peter J. Smith is Reader in the Department of Earth Sciences at the Open University, Milton Keynes, and editor of Open Earth. 